\title{
Sobre os índios Kaciana ${ }^{1}$
}

\author{
Albert Kruse*
}

KRUSE, A. Sobre os índios Kaciana. R. Museu Arq. Etn. 37: 35-37, 2021.

Resumo: Neste texto, Kruse apresenta algumas informações esparsas sobre os Katxuyana, denominados pelo autor como Kaciana, seguidas de uma lista de palavras recolhida na cidade de Óbidos/PA, no ano de 1931, junto a um informante katxuyana que estava então de passagem por aquela cidade.

Palavras-chave: Kaciana; Katxuyana; Trombetas; Amazônia; Língua indígena.

$\mathrm{N}$ Ta tarde de 14 de janeiro de 1931, durante uma caminhada às margens do rio Amazonas em Óbidos/PA, um negro e um índio desembarcaram para me cumprimentar. $\mathrm{O}$ índio pertencia à tribo dos Kaciana. No dia seguinte, a meu pedido, ele apareceu em nossa residência. Como ele falava português relativamente bem, pôde me contar algo sobre seu povo. Antes de tudo, procurei fazer uma pequena lista de palavras dos Kaciana, já que o índio partiria de Óbidos no dia 16.

(1) Os Kaciana vivem à beira do rio Cachorro, um afluente do rio Trombetas. A partir da foz do rio Cachorro, viaja-se ainda por três dias de canoa para chegar à maloca do chefe José. Subindo o Igarapé laskuri, chega-se, em mais três dias, à sede de Colodino (Claudino?), que é o tio de meu informante, Etelvino Vieira. Pode-se, então, chegar aos Kaciana em seis dias, partindo de Óbidos. Nas duas malocas devem morar mais de cem índios.

(2) Os Kaciana andam quase totalmente despidos. Os homens usam o mami e as mulheres, o menenho. Somente as crianças vão banhar-se juntas.

1 Texto originalmente publicado em alemão:

Kruse, A. 1933. Etwas von den Kaciana. Provinzzeitschrift du Franziskanen in Nord-brasilien 1: folhas avulsas.

Tradução: Ingrid Lenk.

* Ordem dos Frades Menores (Ordo Fratum Minorum),

Óbidos, Pará, Brasil.
(3) Os Kaciana vivem da caça, da pesca e da agricultura; esta última é exercida principalmente pelas mulheres. As mulheres são muito boas com a cerâmica. Os homens produzem arcos, flechas, entre outros.

(4) Danças e rituais de puberdade são muito populares. $\mathrm{O}$ chefe pode ter muitas mulheres, o que não é permitido aos outros.

(5) Os conterrâneos de Etelvino são "domesticados" por um negro chamado Sebastião Vieira. Alguns foram catequizados e batizados pelo negro de Cachoeira Porteira. O último sacerdote que saiu de Porteira deve ter sido o irmão (?) Oscar Mello.

(6) Etelvino mencionou outras tribos indígenas, como os Arikena (Arikém), que habitam as margens do Trombeta e são inofensivos. $O$ mesmo não se pode dizer dos Tunayana. Estes devem morar longe (20 dias). Um relato em Santo Antônio faz menção ainda aos Katuena e aos Karacucuana (Cf. Cleven, P. Stanislaus, "Am Strom der Ströme", p. 88).

(7) A curta lista de palavras a seguir mostra que a língua dos Kaciana pertence à família linguística Karib. Ela contém mais elementos Aruak do que a maioria das outras línguas Karib/caribes. Como me foi informado pelo sr. Curt Nimuendajú, não há nada ainda publicado sobre a língua dos Kaciana. 
"Ela se assemelha ao Waiwe (Waiwai, Ouayeoué, Woyaway) do alto do rio Anauá, que por sua vez está muito próxima do dialeto de Nhamundá e Mapuera" (Nimuendajú, comunicação pessoal).

Sobre a pronúncia, deve-se consultar o que foi dito nas Lose Blätter vom Cururu², de abril de 1933. Para os Kaciana, é preciso observar: î = ü (palatal); $\mathrm{x}=\mathrm{ch} ; 1$ ! (“l” seguido de um ponto de exclamação) é um som entre le r, e como não se inicia firme no palato, este som é mantido na região do $\mathrm{R}$ (Cf. Antroposalphabet, 336).

O acento tônico ocorre na última sílaba. Em casos excepcionais, a sílaba é acentuada diferentemente e encontra-se marcada com um ponto de exclamação.

Pequena lista de palavras dos Kaciana

Os futuros missionários de Trombetas poderão melhorar e corrigir estas poucas notas e, principalmente, aumentá-las!

$$
\begin{aligned}
\text { plantação imoho } \\
\text { braço yaçauari } \\
\text { olho yonu ! ru } \\
\text { riacho ahurimuru } \\
\text { banhe-se! eso } \\
\text { local para banho kuetohu } \\
\text { banana haruru } \\
\text { árvore eçu } \\
\text { perna yoçi ! ri } \\
\text { arco pragma } \\
\text { lenha huehotomîtî } \\
\text { irmão yako ! no } \\
\text { peito ohuru } \\
\text { estes motcari } \\
\text { este mokoro } \\
\text { três osoruaul } \\
\text { tu omoro } \\
\text { um tuinari } \\
\text { pato uruma } \\
\text { ele no ! ro } \\
\text { fogo uheçooto } \\
\text { local do fogo tururudpo }
\end{aligned}
$$

2 "Páginas avulsas de Cururu", publicadas na Provinzzeitschrift du Franziskanen in Nord-brasilien.

$$
\begin{aligned}
& \text { dedo nyamo!ri } \\
& \text { peixe kutma } \\
& \text { carne içonodpîre } \\
& \text { rio tuna }
\end{aligned}
$$

saiote feminino menenho

$$
\text { pé poço !ru }
$$

rosto vonatari

Deus Pura

grande aka! ne

cabelo yuhosti

galo kahaitara

pescoço pamarê

mão nyomnyari

pulseira yomekmesti

casa kua! ma

rede otweto

feio nekmane

chefe imatena

chefe patayoto! no

céu kaho

cachorro auare

eu oul

$\operatorname{sim} \mathrm{e}$ ! i

aqueles mokiarî

aquele moke

jovem uahotoike

canoa kana! ua

batata (batata-doce?) Pari

batata Kaschiri Paiya

gato kaikosu

criança Mure

pequeno akandaki

garoto murehoite

tigela de barro tcura! yane

venha! Oko

cabeça yoço!ru

doença uel! ho

maloca kua! ma

mandioca kêtce! re

farinha de mandioca kaiya! ma

homem totó

menina imantaho! rno

menina, mulher jovem imanta cinane 


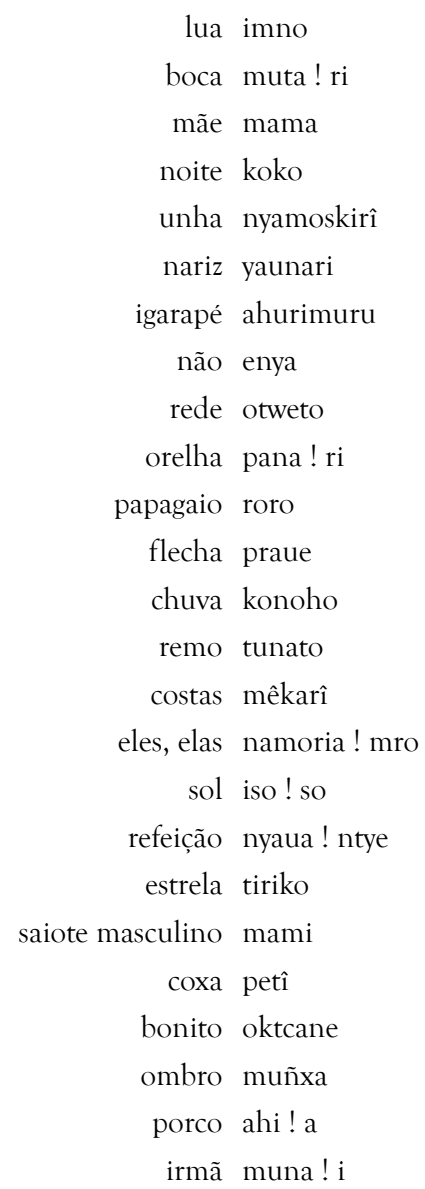

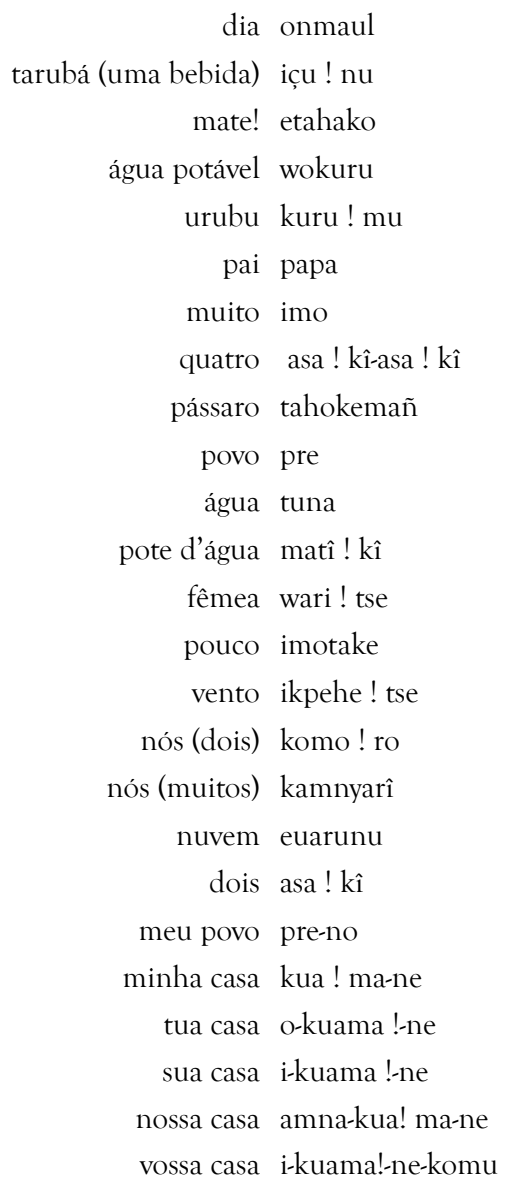

KRUSE, A. About the Kaciana people. R. Museu Arq. Etn. 37: 35-37, 2021.

Abstract: In this chapter, Kruse presents some information about the Katxuyana, whom the author calls Kaciana, followed by a list of words collected in the city of Óbidos, Pará, in 1931, from a Katxuyana informant who was passing through the city.

Keywords: Kaciana; Katxuyana; Trombetas; Amazon; Indigenous language.

\section{Referências bibliográficas}

Cleven, S. P. 1931. Am Strom der Ströme. Erlebnisse e. Amazonas missionars. Franziskus-Druckerei, Werl. 